\title{
AVALIAÇÃO DAS CONDIÇÕES BUCAIS DE IDOSOS INSTITUCIONALIZADOS NO MUNICÍPIO DE MARINGÁ - PR
}

Keli Cristina BERNARDO, Bruna Letícia SCHWAB, Lísia Emi NISHIMORI, Mariana TORMENA, Adriana Márcia BELOTI

Pesquisas demonstram que idosos internos em asilos sentem-se abandonados pelos familiares. Sendo este um dos fatores que interferem nos cuidado próprio, como no caso de má higiene oral. Este estudo teve o objetivo de avaliar as condições bucais e a necessidade de novas próteses dentária para os idosos institucionalizados no Município de Maringá - PR. Esta pesquisa foi realizada entre os meses de Agosto de 2007 e Março de 2008, através do exame físico extra e intra-oral e da aplicação de um questionário composto de perguntas pré-elaboradas, para esta pesquisa, em 82 idosos institucionalizados nos asilos públicos do município de Maringá com 60 anos ou mais de idade. Os dados obtidos a partir dos 82 idosos avaliados, 35 (42,7\%) eram do gênero feminino e 47 $(57,3 \%)$ do gênero masculino. Do total da amostra, $57,3 \%(n=47)$ faziam uso de prótese total removível. Em relação às condições clínicas da prótese, 72,4\% $(n=34)$ apresentaram a prótese em condições inadequadas para o uso. Independente do uso ou não de prótese, dos 82 idosos avaliados, verificou-se que $73,2 \%(n=60)$ apresentavam necessidade de reabilitação no arco superior com prótese total (PT) e 67,1\% ( $n=55)$ necessidade de reabilitação de PT no arco inferior.

Palavras-chave: Prótese total; Assistência a idosos; Exame físico. 